\title{
An integrated cognitive computing approach for systematic conceptual design"
}

\author{
Hao ZHENG ${ }^{1}$, Yi-xiong FENG ${ }^{\dagger 1}$, Jian-rong TAN ${ }^{1}$, Zhi-feng ZHANG ${ }^{1}$, Zi-xian ZHANG ${ }^{2}$ \\ ( ${ }^{1}$ State Key Laboratory of Fluid Power and Mechatronic Systems, Zhejiang University, Hangzhou 310027, China) \\ $\left({ }^{2}\right.$ Hitachi Research Laboratory, Tokyo 152, Japan) \\ †E-mail: fyxtv@zju.edu.cn
}

Received June 3, 2015; Revision accepted Oct. 10, 2015; Crosschecked Mar. 8, 2016

\begin{abstract}
Conceptual design plays an important role in product life cycle, which requires engineers to use sound design theory, cross-disciplinary knowledge, and complex technical support to acquire design concepts. However, the lack of sufficient computational tools makes it difficult for designers to fully explore in the wide design solution spaces. Therefore, this paper proposes an integrated cognitive computing approach to formalize the cognitive activities of conceptual design. A cognitive computing model composed of concept associative memory, concept generation, and decision-making process is established based on the integration of cognitive psychology and engineering design. First of all, the Hopfield neural network is used to acquire similar concept solutions for specific subfunctions from a knowledge base. Then, morphological matrix and genetic algorithm are introduced to produce a set of feasible candidate solutions in the concept generation process. Furthermore, a technique for order preference by similarity to an ideal solution is applied to evaluate the generated concept solutions and obtain the optimal solution automatically. Finally, a case study is given to demonstrate the effectiveness and efficiency of the proposed approach.
\end{abstract}

Key words: Conceptual design, Cognitive computing, Genetic algorithm (GA), Technique for order preference by similarity to ideal solution (TOPSIS)

http://dx.doi.org/10.1631/jzus.A1500161

CLC number: TH122

\section{Introduction}

Conceptual design is a complex, ill-defined, iterative, and creative process that plays a decisive role in the product development process and has major impact on the final product quality (Komoto and Tomiyama, 2012). It has been shown that about

\footnotetext{
¿ Corresponding author

* Project supported by the National Natural Science Foundation of China (Nos. 51322506 and 51205347), the National High-Tech R\&D Program (863 Program) of China (No. 2013AA041303), the National Basic Research Program (973 Program) of China (No. 2011CB706503), and the Zhejiang Provincial Natural Science Foundation of China (No. LR14E050003)

(10) ORCID: Hao ZHENG, http://orcid.org/0000-0003-3259-9153; Yi-xiong FENG, http://orcid.org/0000-0001-7397-2482

(C) Zhejiang University and Springer-Verlag Berlin Heidelberg 2016
}

$80 \%$ of the product life cycle cost is determined during the conceptual design phase (Ullman, 2003). According to various customer requirements and design constraints, designers should apply broad cross-disciplinary knowledge, complicated technical support, and sound design theory to conceive new product ideas. During conceptual design, designers attempt to explore in the wide design space to generate a number of feasible solutions and decide the best concept scheme with a high degree of uncertainty according to customer needs (Gong et al., 2015; Zhang et al., 2015). However, designers always find it difficult to carry out such complicated and multidisciplinary tasks efficiently because of the limited professional knowledge and the extremely timeconsuming and labor-intensive design process (Gao et al., 2014). Thus, it is essential to equip designers with 
efficient approaches and tools and assist them to explore the more comprehensive design space as well as better decisions. Such an issue is receiving increasing attention with the massive growth in multidisciplinary knowledge, since it is becoming more and more difficult for designers to pick up useful knowledge to create satisfactory technical products.

An effective solution to the above issue is to develop a computational computer-aided conceptual design (CACD) system to facilitate designers explore the complicated design space. To realize this, a basic premise is that previous design knowledge in various disciplines can be abstracted from existing cases and preserved in a database for future conceptual design. Unfortunately, although current CACD tools provide major support to embodiment design and detailed design, they fail to provide sufficient help to conceptualization, giving rise to a huge gap in the availability of computational conceptual design tools. In other words, this indicates the importance of developing a computational approach to achieve quantification, formalization, and automation of conceptual design.

In general, the conceptual design process includes the following cognitive activities: problem formulation, seeking alternative solutions, and assessment of results (Brunetti and Golob, 2000). In other words, concept generation and concept evaluation are two primary design cognitive activities that should be performed at the phase of conceptual design. Concept generation is supposed to assist designers to explore combinations of solution principles and acquire satisfactory design alternatives that can meet customer demands. Concept evaluation focuses on assessing various design alternatives obtained from the concept generation process with a high degree of uncertainty. Owing to the focus that these activities are creative and highly intellectual, this paper introduces a computational intelligence method to simulate designers' cognitive processes for realizing design computation.

Researchers have proposed a wide variety of design methods and tools for each activity. Zhang et al. (2005) presented a graph and matrix representation scheme to generate a comprehensive functional model for product functional design through reasoning. Liikkanen and Perttula (2010) introduced memory-based idea generation with modifications for experimentation in conceptual product design. Taura and Nagai (2013) developed a systematized theory and found that the concept generation process could be categorized into two types: first-order concept generation and high-order concept generation. To guide designers in the exploration of design concepts strategically, Chong et al. (2009) developed a general best first heuristic algorithm for CACD. Kim and Yoon (2012) proposed a quality function deployment (QFD) and theory of inventive problem-solving (TRIZ)-based approach to develop concept generation for new product-service systems. Bryant et al. (2005) presented an automated concept generation tool that utilizes the repository of existing design knowledge to generate and evaluate conceptual design variants. Kang and Tang (2013) presented a matrix-based automated concept generation method to analyze the traditional conceptual design phase activities. Zhai et al. (2009) applied grey relation analysis and rough set theory to realize concept evaluation. Malak et al. (2009) proposed an integrated approach combining multiattribute utility theory, set-based design, and the explicit mathematical representation of imprecision for dealing with the uncertainty of conceptual design. Li et al. (2010) proposed a conceptual design process model described by using mathematical language to deal with multistage innovation of product design. Hao et al. (2012) introduced a configurable knowledge component method to support rapid product development process from the perspective of knowledge engineering. Liu and Sun (2008) introduced a semantic representation of design intent for modeling design thinking process. Meanwhile, a few intelligent algorithms were applied to product conceptual design phase, such as neural network, fuzzy set theory, and genetic algorithm (GA). Huang et al. (2006) proposed a novel computational intelligence method to deal with concept generation and concept evaluation. Gero (2000) presented some computational models of creative design containing analogy, emergence, transformation, first principles, and combination as a representative set. Kang and Tang (2014) proposed a novel approach to analyze conceptual design activities. They used similarity theory to analyze the compatibility of two adjacent components, and identified the appropriate design solutions automatically by 
applying ant colony optimization (ACO). Cao et al. (2011) put forward a customer preference model to construct a vector space for concept measurement and applied an ontology-based semantic representation for concept generation.

Although the above approaches have preliminarily made contributions to product conceptual development, they have still some drawbacks in computational conceptual design. First of all, a systematic product conceptual design encompassing concept generation, combination, and evaluation from the perspective of design cognition is rarely discussed. Second, how to process uncertainty demand in the conceptual design is still worthy of further research. Meanwhile, although cognitive methods have received considerable interest from scholars, current researches are still in the early stage.

According to the above limitations, this paper proposes an integrated cognitive computing approach to formalize the cognitive activities of conceptual design. First, by analyzing the designers' thinking process and characteristics in conceptual design, a cognitive computing model is established, incorporating cognitive psychology and engineering design, which is composed of concept associative memory, concept generation, and the decision-making process. The Hopfield neural network is used to acquire similar concept solutions for specific subfunctions from knowledge base. Then, morphological matrix and GA are introduced to produce a set of feasible candidate solutions in the concept generation process. Furthermore, a technique for order preference by similarity to an ideal solution (TOPSIS) is applied to evaluate the generated concept solutions and obtain the optimal solution automatically. The effectiveness and efficiency of the proposed approach are verified by a case study. The main purpose of this study is to realize the formalization of computational conceptual design incorporating cognitive psychology and engineering design to acquire feasible concept solutions for further product development.

\section{Cognitive computing model of conceptual design}

Conceptual design is a creative, complex, and iterative decision-making process. Based on customer demand, it is also a cognitive process to acquire the best candidates, and serves as a starting point for further product development. To develop a computational conceptual design system, there must be a model describing the entire process of conceptual design. This paper proposes a cognitive computing model of conceptual design that is composed of four major cognitive activities, namely, analysis, generation, composition, and evaluation, as shown in Fig. 1. Analysis aims at understanding the problem and defining the constraints and evaluation criteria. As a part of problem analysis, a function model is determined. Generation involves generating a function structure. Based on the problem requirements and constraints, designers acquire relevant knowledge and information from their memories to create initial design solutions. Composition involves the evolution of initial ideas into satisfactory concepts, which takes place when designers combine new concepts generated from their mind. Evaluation aims to assess the composed concepts by design criteria, constraints, and requirements.

In this paper, according to the knowledge base including the information about alternative principles for various mechanical functions, different function structure units are first generated by the Hopfield neural network. To avoid combination explosion, an approach based on morphological matrix and GA is proposed and a set of satisfactory concepts with better performance is obtained through the evolution process. Then, the TOPSIS (a more detailed description on TOPSIS is given in Section 3.3) is applied to evaluate the generated concepts according to uncertain customer demands, and the optimal concept is acquired as a result of conceptual design. Although the optimal solution may not be adopted finally, it could assist designers to create useful ideas, determine appropriate candidate solutions, or seek more detailed information for specific customer requirements.

\section{Computational conceptual design stimulation}

\subsection{Concept generation based on Hopfield neural network}

By means of problem analysis, the functional model and subfunctional chain are generated. 


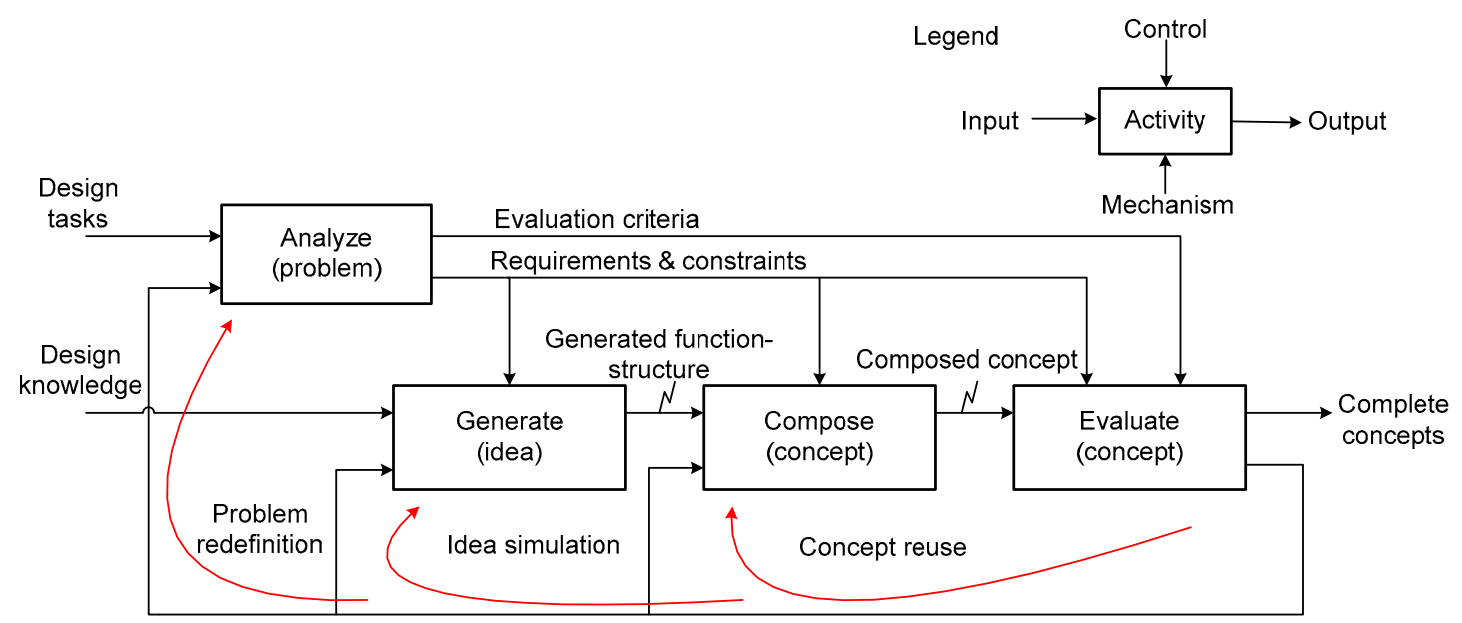

Fig. 1 Cognitive model of conceptual design

Functional model is a prerequisite for conceptual design, and it is defined as a process of decomposing the main function of a product into subfunctions. Meanwhile, a functional basis is used to represent the function model, which is characterized in a verbobject format to guarantee that other designers can read and understand it.

For specific subfunctions, designers search for mapping structures to solve problems with the guidance of pre-existing knowledge and experience. The Hopfield neural network simulates human cognitive behavior, which can use previous experience and pre-existing knowledge to solve new problems. Suppose the sample vector is $\left(u_{1}, u_{2}, \ldots, u_{m}\right)$ and the function vector $\boldsymbol{u}_{0}=\left(u_{01}, u_{02}, \ldots, u_{0 n}\right)$ describing customer demands is the input vector of the Hopfield neural network. The Hebb algorithm is used to acquire the associative matrix, as shown in Eq. (1). When the vectors of the sample intersect, it means that each sample has reached a steady state and can associate similar solution.

$$
\boldsymbol{w}=\frac{1}{n} \sum_{k=1}^{m}\left(\boldsymbol{u}_{k} \boldsymbol{u}_{k}^{\mathrm{T}}-\boldsymbol{I}\right)
$$

where $\boldsymbol{I}$ is the cell matrix, $n$ is the number of subfunctions, $m$ is the number of samples, $\boldsymbol{u}_{k}$ represents the $k$ th sample vector, and $\boldsymbol{u}_{k}^{\mathrm{T}}$ is the transposed matrix of $\boldsymbol{u}_{k}$.

Function vector is regarded as the initial iteration of the Hopfield neural network, and the iterative formula is represented by Eq. (2). When the network status reaches a steady state, the associative outputs for the subfunctions can be obtained.

$$
\left\{\begin{array}{l}
\boldsymbol{v}_{i}^{0}=\boldsymbol{u}_{0 i}, \\
\boldsymbol{v}_{i}^{k+1}=\operatorname{sgn}\left[\sum_{j=1}^{n} w_{i j} \boldsymbol{v}_{j}^{k}-\theta_{i}\right],
\end{array}\right.
$$

where $\theta_{i}$ is the threshold value of the associative matrix, $w_{i j}$ means the connection weight between the neurons $i$ and $j, \boldsymbol{v}_{i}$ represents the state of the neuron $i$ $(i=1,2, \ldots, n), \boldsymbol{v}_{i}^{k}$ is the state of the neuron $i$ after $k$ iterations, and

$$
\operatorname{sgn}(x)= \begin{cases}-1, & x<0 \\ 1, & x>0\end{cases}
$$

\subsection{Concept composition based on morphological matrix and GA}

Morphology simulates the thinking style of human beings to solve problems, and its focus is to search for a feasible solution to the corresponding problem by trying out all possible combinations systematically in a matrix. The morphological matrix is established by decomposing the global function of the product into subfunctions, which are listed on the vertical axis of the matrix. It is used to obtain all possible solutions to the corresponding problem. A case study of a morphological matrix for hydraulic press is given in Section 4.

Suppose there are $n$ function units according to the decomposition of the product function and we can 
acquire $m$ mapping structures for each function unit by association. Hence, the designers will have $m^{n}$ design results through concept composition, and if inspired, they will acquire even more. In this study, GA is used to stimulate concept combination. A flowchart is presented in Fig. 2 to show the stimulation. GA is regarded as a stochastic search technique according to the mechanism of natural genetics and natural selection (Renner and Ekárt, 2003). It can avoid the combination explosion problem caused by blind search. The search space means coded solutions to specific problem, and the solution space represents actual solutions to it. During this process, the subfunction concept alternatives will be first encoded by means of a binary string. Suppose a subfunction is achieved by four concepts. Then, the corresponding alternative structures could be described by two-digit binary strings, namely, $00,01,10$, and 11 . Individual fitness is computed according to the fitness of the function unit. The fitness is formulated as Fitness $_{i}\left(F_{i}\left(M_{1}, M_{2}, \ldots\right)\right.$, Function $)$, where Fitness $i$ is the fitness of function unit $i$, which can be acquired from the database, and $F_{i}\left(M_{1}, M_{2}, \ldots\right)$ represents all the corresponding structure units $(M)$ in function unit $i$. A set of satisfied concepts is acquired as the outcome of the concept generation phase.

\subsection{Concept evaluation for selecting the optimal output based on fuzzy TOPSIS}

TOPSIS is a kind of multiple-criteria decisionmaking method to assess a set of alternative solutions according to simultaneous maximization of distance from a nadir point and minimization of distance from an ideal point (Olson, 2004). The traditional TOPSIS can process only quantitative evaluation indexes but not qualitative customer demands in which the evaluation information and most performance indexes are uncertain and vague (Wang et al., 2012). It is always based on the concept that the selected alternative should have the farthest distance from the nadir point and the shortest distance from the ideal point. To solve the problem, a fuzzy TOPSIS approach integrating triangular fuzzy number and linguistic variables is proposed to generate the overall score for each candidate. According to the concrete design requirements, an effective evaluation indicator system composed of economic index, technical index, and social index is first developed, which is indicated in Fig. 3. Designers assess the design solution according to the comprehensive consideration of these parameters and choose the best one.

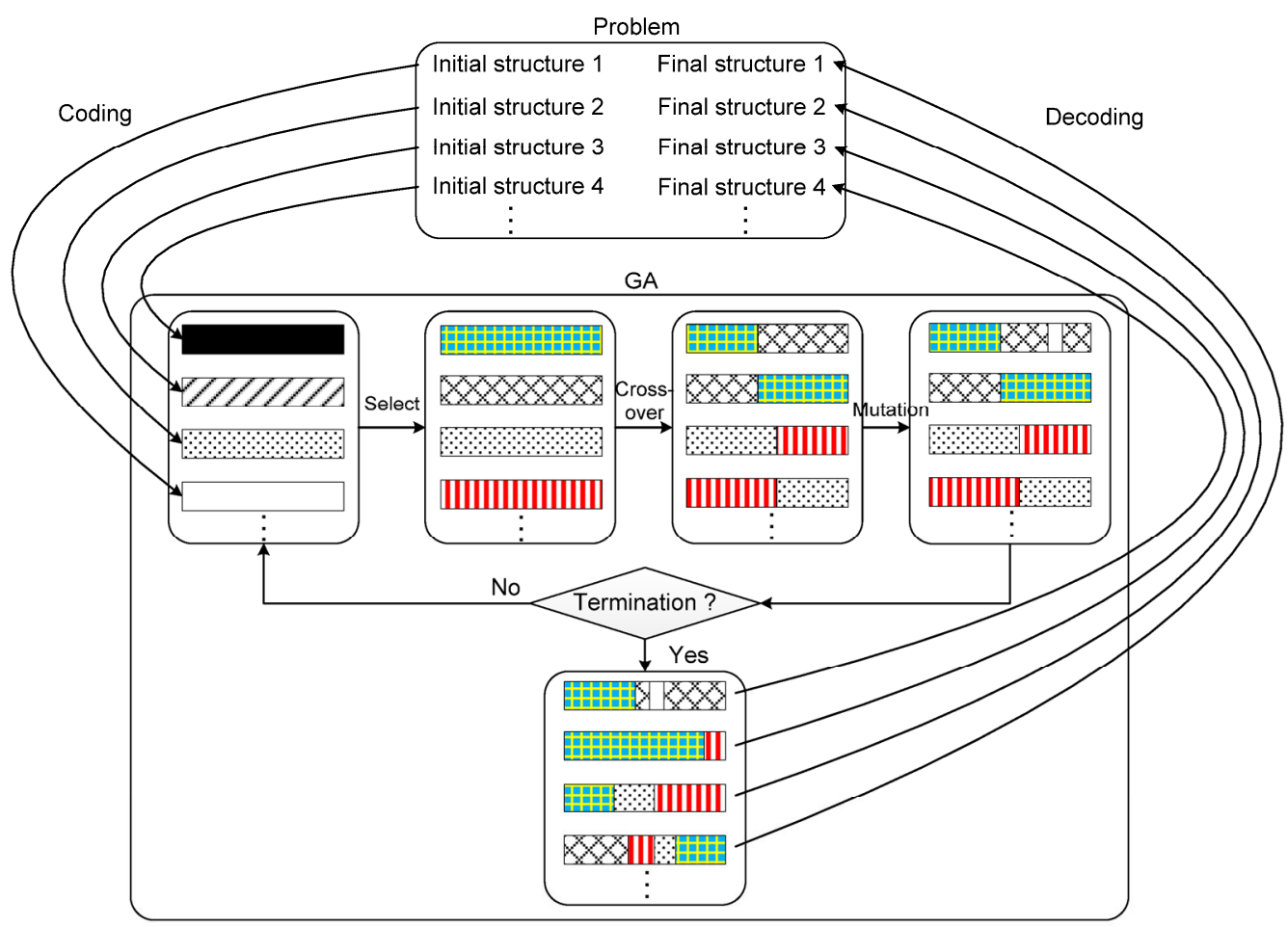

Fig. 2 Flow chart of GA-based concept composition process 


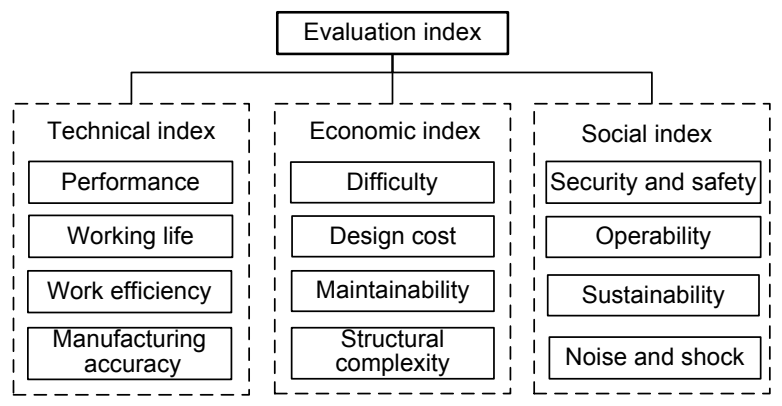

Fig. 3 Evaluation index

This study uses triangular fuzzy number to describe the uncertainty of customer demands. A triangular fuzzy number usually can be represented as $\tilde{a}=(a, b, c)$, and its membership function, $\mu_{\tilde{a}}$, can be described as given in Eq. (3). In fuzzy theory, the scale transformation method is applied to convert linguistic variables to fuzzy numbers, and the relationship between them is shown in Table 1 .

$$
\mu_{\tilde{a}}(x)= \begin{cases}0, & x \leq a, \\ \frac{x-a}{b-a}, & a<x<b, \\ \frac{c-x}{b-c}, & b \leq x<c, \\ 0, & x \geq c .\end{cases}
$$

Table 1 Linguistic variables and fuzzy evaluation

\begin{tabular}{cc}
\hline Linguistic variable & Fuzzy evaluation \\
\hline Very poor & $(0,0,0.25)$ \\
Poor & $(0,0.25,0.5)$ \\
General & $(0.25,0.5,0.75)$ \\
Good & $(0.5,0.75,1)$ \\
Very good & $(0.75,1,1)$ \\
\hline
\end{tabular}

By computing the distance between the evaluation object and the ideal or nadir alternative, the best solution close to the ideal alternative and far away from nadir alternative can be acquired. Suppose $A=\left\{A_{1}, A_{2}, \ldots, A_{m}\right\}$ is an alternative solution set, $G=\left\{G_{1}, G_{2}, \ldots, G_{n}\right\}$ is an attributive set, and $\boldsymbol{w}=\left[w_{1}\right.$, $\left.w_{2}, \ldots, w_{n}\right]^{\mathrm{T}}$ is the weight vector of evaluation index attribute. The decision process can be divided into six steps.

Step 1: Compute fuzzy evaluation and weight. Suppose the fuzzy evaluation of $T$ decision-makers is

$$
\begin{gathered}
\tilde{y}_{i j k}=\left(a_{i j k}, b_{i j k}, c_{i j k}\right), \\
i=1,2, \cdots, m, j=1,2, \cdots, n, k=1,2, \cdots, T .
\end{gathered}
$$

Then, the fuzzy evaluation of each index is given by

$$
a_{i j}=\min \left\{a_{i j k}\right\}, b_{i j}=\frac{1}{T} \sum_{k=1}^{T} b_{i j k}, c_{i j}=\max \left\{c_{i j k}\right\} .
$$

The fuzzy weight is given by

$$
\begin{gathered}
\tilde{w}_{j}=\left(w_{1 j}, w_{2 j}, w_{3 j}\right), \\
w_{1 j}=\min \left\{w_{1 j k}\right\}, w_{2 j}=\frac{1}{T} \sum_{k=1}^{T} w_{2 j k}, w_{3 j}=\max \left\{w_{3 j k}\right\} .
\end{gathered}
$$

Step 2: Construct normalized decision-making matrix $\boldsymbol{Y}=\left[y_{i j}\right]_{m \times n}$. The weighting decision-making matrix is $z=\left[z_{i j}\right]_{m \times n}, i=1,2, \ldots, m, j=1,2, \ldots, n$; $z_{i j}=\tilde{w}_{j} \cdot y_{i j}$.

$$
y_{i j}=\left(\frac{a_{i j}}{c_{j}^{+}}, \frac{b_{i j}}{c_{j}^{+}}, \frac{c_{i j}}{c_{j}^{+}}\right), \quad i=1,2, \cdots, m, j=1,2, \cdots, n,
$$

where $c_{j}^{+}$is the positive indicator.

Step 3: Identify the ideal alternative $A^{+}$and the nadir alternative $A^{-}$. Define the ideal alternative as $A^{+}=\left(z_{1}^{+}, z_{2}^{+}, \cdots, z_{n}^{+}\right)$and the nadir alternative as $A^{-}=\left(z_{1}^{-}, z_{2}^{-}, \cdots, z_{n}^{-}\right)$; then the ideal alternative and nadir alternative can be described as follows:

$$
\begin{cases}z_{j}^{+}=\max _{i} z_{i j}, & i=0,1, \cdots, m, j=0,1, \cdots, n, \\ z_{j}^{-}=\min _{i} z_{i j}, & i=0,1, \cdots, m, j=0,1, \cdots, n .\end{cases}
$$

Step 4: Develop a distance measure from each criterion to both the ideal $\left(d^{+}\right)$and the nadir $\left(d^{-}\right)$ alternatives:

$$
\begin{aligned}
& d_{i}^{+}=\left\|z_{i}-A^{+}\right\|=\sum_{j=1}^{n} d_{\mathrm{v}}\left(\tilde{z}_{i j}, \tilde{z}_{j}^{+}\right), \quad i=1,2, \cdots, m, \\
& d_{i}^{-}=\left\|z_{i}-A^{-}\right\|=\sum_{j=1}^{n} d_{\mathrm{v}}\left(\tilde{z}_{i j}, \tilde{z}_{j}^{-}\right), \quad i=1,2, \cdots, m,
\end{aligned}
$$


where $d_{\mathrm{v}}(\tilde{a}, \tilde{b})=\sqrt{\frac{1}{3} \sum_{i=1}^{3}\left(a_{i}-b_{i}\right)^{2}}$ represents the distance between the triangular fuzzy numbers $\tilde{a}$ and $\tilde{b}$.

Step 5: Determine the ratio $c$, which is equal to the distance to the nadir alternative divided by the sum of the distances to the ideal alternative and to the nadir alternative, which are obtained by Eqs. (8) and (9):

$$
c_{i}=\frac{d_{i}^{-}}{d_{i}^{+}+d_{i}^{-}}, \quad i=1,2, \cdots, m
$$

Step 6: Sequence the solution $A_{i}$ according to Eq. (10), and choose the best solution. A larger $c_{i}$ value indicates better comprehensive performance. Thus, the largest $c_{i}$ value is selected as the best solution from the given solution set.

\section{Case study}

A hydraulic press is used as a case study to explain the proposed computational conceptual design approach in this section. Hydraulic press is a type of manufacturing equipment in industry that utilizes hydraulic transmission technology to machines made up of nonmetals or metals. It is used in various fields, such as sheet stamping, forging, hot pressing, and powder metallurgy. Fig. 4 shows the instance and virtual model of a hydraulic machine with four columns. As the hydraulic press has got wider applications in manufacturing and production, its conceptual design draws more and more attention from manufacturers and customers. The conceptual design of a hydraulic press requires designers to equip themselves with broad cross-disciplinary knowledge, and the use of computers will enable them to better accomplish the task. This paper takes the design of a hydraulic press as an example to illustrate the proposed method. The programs of GA algorithm and decision-making algorithm are run in a desktop computer with a dual $2.63-\mathrm{GHz}$ Intel i5 processor and 8-GB RAM, which are formulated using the Matlab toolbox.

At the initial phase of conceptual design, designers analyze the design requirements and con- sumer demands to decide incentive variables and design constraints. According to the subfunctions, association helps to establish the mapping between every function and its substructures. The structural solution is stored in the knowledge base as human memory. Table 2 shows the structural solution of the function units based on pre-existing design knowledge and experience of the hydraulic press.

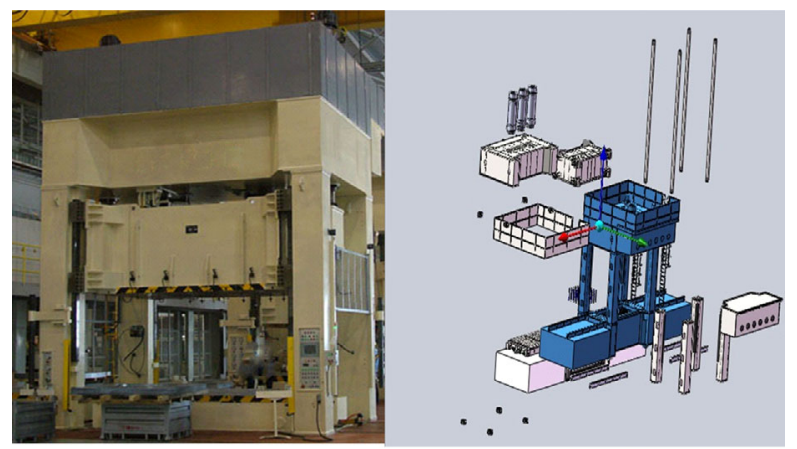

Fig. 4 Instance and explosion modeling of hydraulic press

Table 2 Morphology matrix of principle solutions of hydraulic press

\begin{tabular}{|c|c|}
\hline $\begin{array}{l}\text { Function } \\
\text { unit }\end{array}$ & Solution set \\
\hline 1 Motion & $\begin{array}{l}\text { Plunger-type cylinder }\left(\mathrm{S}_{11}\right) \text {, piston cylinder } \\
\left(\mathrm{S}_{12}\right) \text {, differential plunger hydraulic cyl- } \\
\text { inder }\left(\mathrm{S}_{13}\right)\end{array}$ \\
\hline 2 Guide & $\begin{array}{l}45 \mathrm{C} \text { plunger }\left(\mathrm{S}_{21}\right), 50 \mathrm{C} \text { plunger }\left(\mathrm{S}_{22}\right) \text {, cast } \\
\text { iron plunger }\left(\mathrm{S}_{23}\right)\end{array}$ \\
\hline $\begin{array}{l}3 \text { Mating } \\
\text { guide }\end{array}$ & $\begin{array}{l}\text { Alloy guide sleeve }\left(\mathrm{S}_{31}\right) \text {, nylon guide sleeve } \\
\qquad\left(\mathrm{S}_{32}\right)\end{array}$ \\
\hline 4 Seal & $\begin{array}{l}\text { V-type sealing }\left(\mathrm{S}_{41}\right) \text {, U-type sealing }\left(\mathrm{S}_{42}\right) \text {, } \\
\text { Y-type sealing }\left(\mathrm{S}_{43}\right) \text {, O-type sealing }\left(\mathrm{S}_{44}\right)\end{array}$ \\
\hline 5 Bearing & $\begin{array}{l}\text { Modular framework }\left(\mathrm{S}_{51}\right) \text {, integral type } \\
\text { frame }\left(\mathrm{S}_{52}\right) \text {, concrete frame }\left(\mathrm{S}_{53}\right)\end{array}$ \\
\hline
\end{tabular}

After coding and population initialization, designers should set the number of function units $n=5$. Here the evaluation indexes must meet the basic functions of high efficiency and low cost. The weight factors of the five subfunctions are $0.17,0.13,0.2,0.3$, and 0.20 , respectively. Then, the fitness of each concept individual could be calculated based on the related evaluation knowledge stored in the database. The average fitness of the solution can be obtained as follows:

Fitness $=w_{1}$ Fitness $_{1}+w_{2}$ Fitness $_{2}+\ldots+w_{5}$ Fitness $_{5}$. 
Set the mutation rate $P_{\mathrm{m}}=0.02$, crossover rate $P_{\mathrm{c}}=0.95$, population size $N=200$, and generation $K=200$. If the average fitness value of the population stops increasing, the algorithm ends. Fig. 5 shows the evolutionary process of GA. Finally, five schemes with relatively high fitness value are chosen for subsequent concept generation stage as shown in Table 3. According to the method proposed in Section 3.3, the calculated values are represented by fuzzy numbers and the fuzzy evaluation matrix increases. The result indicates that the optimal scheme for the hydraulic press design is as follows: motion, differential plunger hydraulic cylinder; guide, $50 \mathrm{C}$ plunger; mating guide, alloy guide sleeve; seal, O-type sealing; bearing, modular framework.

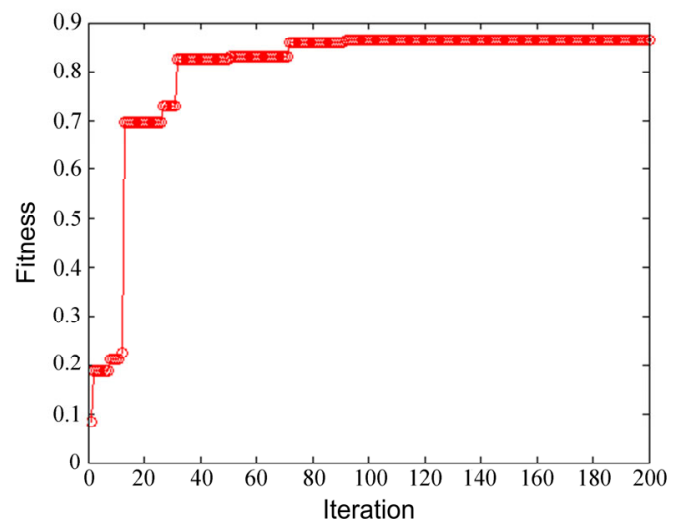

Fig. 5 GA-based concept composition process

Table 3 Computation result of concept generation process

\begin{tabular}{ccc}
\hline No. & Design result & Fitness \\
\hline 1 & $\mathrm{~S}_{13}+\mathrm{S}_{22}+\mathrm{S}_{31}+\mathrm{S}_{44}+\mathrm{S}_{51}$ & 0.834 \\
2 & $\mathrm{~S}_{11}+\mathrm{S}_{22}+\mathrm{S}_{31}+\mathrm{S}_{41}+\mathrm{S}_{53}$ & 0.789 \\
3 & $\mathrm{~S}_{13}+\mathrm{S}_{23}+\mathrm{S}_{31}+\mathrm{S}_{43}+\mathrm{S}_{52}$ & 0.756 \\
4 & $\mathrm{~S}_{12}+\mathrm{S}_{21}+\mathrm{S}_{32}+\mathrm{S}_{41}+\mathrm{S}_{52}$ & 0.688 \\
5 & $\mathrm{~S}_{13}+\mathrm{S}_{22}+\mathrm{S}_{32}+\mathrm{S}_{42}+\mathrm{S}_{52}$ & 0.558 \\
\hline
\end{tabular}

\section{Conclusions}

Conceptual design process is often timeconsuming and labor-intensive. Current CACD tools provide major support to embodiment design and detailed design, but they fail to provide sufficient help to conceptualization. Furthermore, even if designers have sufficient knowledge, it may be difficult to acquire satisfactory solutions efficiently if not guided by computers. Based on the above understandings, this paper proposed an integrated cognitive computing approach based on the integration of engineering design and cognitive psychology, which is composed of concept associative memory, concept generation, and the decision-making process. The Hopfield neural network, GA, and TOPSIS were applied to obtain the best solution. The effectiveness and efficiency of the approach are verified by a case study of conceptual design. Although they may not be used finally, the theoretical optimal solutions could assist designers to obtain the list of satisfactory candidate solutions or explore more useful information for detailed design.

The main limitation of the proposed approach is that all functions should have predefined alternatives, which are stored in the database. To expand the applicability of our approach, further research will focus on big data-based product conceptualizing approaches encompassing design data acquisition, representation, and application.

\section{References}

Brunetti, G., Golob, B., 2000. A feature-based approach towards an integrated product model including conceptual design information. Computer-Aided Design, 32(14):877887. http://dx.doi.org/10.1016/S0010-4485(00)00076-2

Bryant, C.R., McAdams, D.A., Stone, R.B., 2005. A computational technique for concept generation. ASME International Design Engineering Technical Conferences and Computers and Information in Engineering Conference, American Society of Mechanical Engineers, p.267-276.

Cao, D.X., Li, Z.J., Ramani, K., 2011. Ontology-based customer preference modeling for concept generation. $A d$ vanced Engineering Informatics, 25(2):162-176. http://dx.doi.org/10.1016/j.aei.2010.07.007

Chong, Y.T., Chen, C.H., Leong, K.F., 2009. A heuristicbased approach to conceptual design. Research in Engineering Design, 20(2):97-116. http://dx.doi.org/10.1007/s00163-008-0059-9

Gao, Y.C., Feng, Y.X., Tan, J.R., 2014. Multi-principle preventive maintenance: a design-oriented scheduling study for mechanical systems. Journal of Zhejiang University-SCIENCE A (Applied Physics \& Engineering), 15(11):862-872. http://dx.doi.org/10.1631/jzus.A1400102

Gong, X., Feng, Y.X., Ren, Z.W., et al., 2015. An adaptive design method for understanding tolerance in the precision stamping process. Journal of Zhejiang University-SCIENCE A (Applied Physics \& Engineering), 16(5):387-394.

http://dx.doi.org/10.1631/jzus.A1400220

Gero, J.S., 2000. Computational models of innovative and creative design processes. Technological Forecasting and 
Social Change, 64(2-3):183-196.

http://dx.doi.org/10.1016/S0040-1625(99)00105-5

Hao, J., Yang, H.C., Yan, Y., et al., 2012. Configurable knowledge component technology oriented to product design tasks. Computer Integrated Manufacturing Systems, 18(4):705-712 (in Chinese). http://dx.doi.org/10.13196/j.cims.2012.04.35.haoj.020

Huang, H.Z., Bo, R., Chen, W., 2006. An integrated computational intelligence approach to product concept generation and evaluation. Mechanism and Machine Theory, 41(5):567-583.

http://dx.doi.org/10.1016/j.mechmachtheory.2005.07.006

Kang, Y., Tang, D., 2013. Matrix-based computational conceptual design with ant colony optimization. Journal of Engineering Design, 24(6):429-452. http://dx.doi.org/10.1080/09544828.2012.756461

Kang, Y., Tang, D., 2014. An approach to product solution generation and evaluation based on the similarity theory and ant colony optimisation. International Journal of Computer Integrated Manufacturing, 27(12):1090-1104. http://dx.doi.org/10.1080/0951192X.2013.855945

Kim, S., Yoon, B., 2012. Developing a process of concept generation for new product-service systems: a QFD and TRIZ-based approach. Service Business, 6(3):323-348. http://dx.doi.org/10.1007/s11628-012-0138-x

Komoto, H., Tomiyama, T., 2012. A framework for computeraided conceptual design and its application to system architecting of mechatronics products. Computer-Aided Design, 44(10):931-946. http://dx.doi.org/10.1016/j.cad.2012.02.004

Li, W.Q., Li, Y., Wang, J., et al., 2010. The process model to aid innovation of products conceptual design. Expert Systems with Applications, 37(5):3574-3587. http://dx.doi.org/10.1016/j.eswa.2009.10.034

Liikkanen, L.A., Perttula, M., 2010. Inspiring design idea generation: insights from a memory-search perspective. Journal of Engineering Design, 21(5):545-560. http://dx.doi.org/10.1080/09544820802353297

Liu, J.H., Sun, Z.Y., 2008. Representing design intents for design thinking process modelling. In: BEng, X.T.Y., Ion, W.J. (Eds.), Global Design to Gain a Competitive Edge. Springer London, UK, p.187-197. http://dx.doi.org/10.1007/978-1-84800-239-5_19

Malak, R.J., Aughenbaugh, J.M., Paredis, C.J.J., 2009. Multiattribute utility analysis in set-based conceptual design. Computer-Aided Design, 41(3):214-227. http://dx.doi.org/10.1016/j.cad.2008.06.004

Olson, D.L., 2004. Comparison of weights in TOPSIS models. Mathematical and Computer Modelling, 40(7-8):721-727. http://dx.doi.org/10.1016/j.mcm.2004.10.003

Renner, G., Ekárt, A., 2003. Genetic algorithms in computer aided design. Computer-Aided Design, 35(8):709-726. http://dx.doi.org/10.1016/S0010-4485(03)00003-4

Taura, T., Nagai, Y., 2013. A systematized theory of creative concept generation in design: first-order and high-order concept generation. Research in Engineering Design, 24(2):185-199.

http://dx.doi.org/10.1007/s00163-013-0152-6
Ullman, D., 2003. The Mechanical Design Process, 3rd Edition. McGraw-Hill, USA, p.132-156.

Wang, Y., Ma, X.L., Wang, Y.H., et al., 2012. Location optimization of multiple distribution centers under fuzzy environment. Journal of Zhejiang University-SCIENCE A (Applied Physics \& Engineering), 13(10):782-798. http://dx.doi.org/10.1631/jzus.A1200137

Zhai, L.Y., Khoo, L.P., Zhong, Z.W., 2009. Design concept evaluation in product development using rough sets and grey relation analysis. Expert Systems with Applications, 36(3):7072-7079.

http://dx.doi.org/10.1016/j.eswa.2008.08.068

Zhang, W.Y., Tor, S.B., Britton, G.A., 2005. A graph and matrix representation scheme for functional design of mechanical products. The International Journal of $A d$ vanced Manufacturing Technology, 25(3-4):221-232. http://dx.doi.org/10.1007/s00170-003-1827-3

Zhang, Z.F., Feng, Y.X., Tan, J.R., et al., 2015. A novel approach for parallel disassembly design based on a hybrid fuzzy-time model. Journal of Zhejiang UniversitySCIENCE A (Applied Physics \& Engineering), 16(9):724736.

http://dx.doi.org/10.1631/jzus.A1500155

\section{中文概要}

题 目: 一种面向系统化概念设计的集成认知计算方法

目 的: 产品概念设计是一种复杂的认知活动过程, 在产 品生命周期中具有极其重要的作用。目前对产品 概念设计的智能化方向主要集中在概念生成与 评价等离散阶段, 尚缺乏系统性的智能化概念设 计方法。本文的目的是在形式化与系统化概念设 计过程中, 实现设计的计算化与智能化, 支持计 算机辅助设计的发展与应用。

创新点: 1. 结合工程设计与认知科学, 提出多阶段设计认 知模型表达产品设计过程; 2. 采用计算智能算 法, 实现设计认知模型的智能求解。

方 法: 1. 通过分析设计者的设计过程规律, 结合认知心 理学构建符合设计流程的多阶段设计认知模型 （图 1)；2. 通过引入计算智能算法, 分别对认 知模型中概念联想、概念组合和方案评价进行认 知计算, 实现设计过程的正向求解 (图 2); 3. 通 过仿真模拟, 运用认知计算方法对液压机产品进 行概念设计求解, 得到相关的设计方案, 并验证 所提方法的可行性和有效性（表 3）。

结 论: 1. 产品概念设计过程可抽象为概念生成、概念组 合和方案评价的认知过程; 2 . 认知过程可以引入 计算智能方法对其进行分别模拟计算; 3. 运用认 知计算方法对产品进行概念设计, 可以显著提高 设计效率，同时有助于设计自动化的实现。

关键词: 概念设计; 认知计算; 遗传算法; 优劣解距离法 